\title{
10 health stories that mattered: Oct.18-24
}

- The House of Commons health committee released a report on marijuana's health risks and harms, including the drug's negative impact on brain development and possible links to psychiatric problems. The report did not comment on the medical marijuana debate, prompting concern that the Conservatives had whitewashed evidence that conflicted with their stance against the drug.

- Health Canada has lifted the import ban on more than 40 "medically necessary" drugs from three factories in India, despite unresolved issues at the plants. The regulator said the drugs can be sold in Canada after they undergo testing by an independent third party.

- The Canadian Centre on Substance Abuse wants the federal government to include alcohol in its \$570-million National Anti-Drug Strategy, according to a brief submitted to the House of Commons finance committee. The brief states that alcohol causes more deaths than lung cancer and more hospital stays than all other substances combined.
- The Canadian Public Health Association called on the federal government to undertake a national inquiry into missing and murdered Aboriginal women. The association also urged the government to implement a violence-prevention action plan that is recommended by the World Health Organization.

- Health Canada endorsed the use of Aspirin as an emergency treatment for heart attacks. The regulator will allow pharmaceutical company Bayer Inc. to claim that chewing two 81-mg Aspirin tablets "may help save your life if you think you are having a heart attack."

- Canada auctioned \$1.5 million in medical supplies, including isolation gowns, even after the World Health Organization requested the gear to equip frontline workers battling Ebola in West Africa, according to the Globe and Mail.

- A medical clinic in Edmonton is blurring the lines between public and private services, according to a provincial audit obtained by the Edmonton
Journal. Auditors cited "extra billing and some documentation issues," among other concerning practices.

- The federal government will stop sending Canadian health workers to fight Ebola in West Africa until there is a guarantee that they can be evacuated if they get sick, Health Minister Rona Ambrose told reporters. She said the countries most affected don't have the capacity to deal with an influx of health workers who could become infected with the virus.

- A British Columbia man with asthma died after contracting enterovirus D68, a virus that causes respiratory illness. It's thought to be the first Canadian death from the virus.

- Health Canada reported that more than 200 Canadians have been infected with chikungunya, a virus transmitted by mosquitos. The virus has afflicted hundreds of thousands of people in the Caribbean. The Canadian cases stem from travel to the region. - Lauren Vogel, CMAJ

CMAJ 2014. DOI:10.1503/cmaj.109-4930 